\title{
Pathogenic potential of Shiga toxin- producing Escherichia coli strains of caprine origin: virulence genes, Shiga toxin subtypes, phylogenetic background and clonal relatedness
}

Maziar Jajarmi ${ }^{1}$, Mahdi Askari Badouei ${ }^{2}$, Abbas Ali Imani Fooladi ${ }^{1}$, Reza Ghanbarpour ${ }^{3^{*}+}$ and Ali Ahmadi ${ }^{4^{*}+}$ (D)

\begin{abstract}
Background: All over the world, Shiga toxin-producing Escherichia coli (STEC) are considered as important zoonotic pathogens. Eight serogroups have the greatest role in the outbreaks and diseases caused by STEC which include O26, O45, O103, O111, O113, O121, O145 and 0157. Ruminants, especially cattle are the main reservoirs but the role of small ruminants in the epidemiology of human infections has not been thoroughly assessed in many countries. The objective of this research was to investigate the pathogenic potential of the STEC strains isolated from slaughtered goats. In this study, a total of 57 STEC strains were recovered from 450 goats and characterized by subtyping of stx genes, O-serogrouping, phylo-typing and DNA fingerprinting.

Results: Amongst 57 STEC strains isolated from goats, the prevalence of st $\times 1$ was significantly more than stx2 (98. $2 \%$ vs. $24.5 \% ; P \leq 0.05)$, and $22.8 \%$ of strains harbored both $s t \times 1$ and st $\times 2$ genes. Three (5.2\%) isolates were characterized as EHEC, which carried both eae and stx genes. A total of five stx-subtypes were recognized namely: stx1c (94.7\%), stx1a (53.7\%), stx2d (21\%), stx2c (17.5\%), and stx2a (15.7\%). In some parts of the world, these subtypes have been reported in relation with severe human infections. The stx subtypes predominantly occurred in four

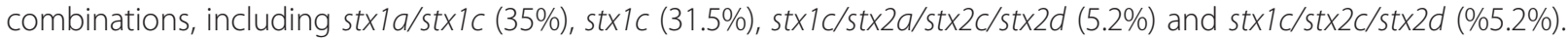
In serogrouping, the majority of STECs from goats did not belong to the top 8 serogroups but two strains belonged to 0113 , which has been recognized as an important pathogenic STEC in Australia. Interestingly, none of stx $^{+} e^{+} e^{+}$isolates belonged to the tested serogroups. In phylo-typing the isolates mostly belonged to phylo-group B1 (82.4\%), followed by phylo-group A (12.3\%). STEC strains showed a substantial diversity in DNA fingerprinting; there were 24 unique ERIC-types (with a $\geq 95 \%$ similarity) among the isolates.
\end{abstract}

Conclusions: Despite the fact that the top 8 STEC serogroups were uncommon in caprine strains, the presence of highly pathogenic stx subtypes indicates that small ruminants and their products can be considered as an overlooked public health risk for humans, especially in developing countries which consume traditional products.

Keywords: Goats, phylogeny, serogroup, Shiga-toxin producing Escherichia coli, subtype

\footnotetext{
* Correspondence: ghanbar@uk.ac.ir; aliahmadi@bmsu.ac.ir

${ }^{\dagger}$ Equal contributors

${ }^{3}$ Molecular Microbiology Research Group, Shahid Bahonar University of

Kerman, Kerman, Iran

${ }^{4}$ Molecular Biology Research Center, Systems Biology and Poisonings

Institute, Baqiyatallah University of Medical Sciences, Tehran, Iran

Full list of author information is available at the end of the article
} 


\section{Background}

Shiga toxin-producing Escherichia coli (STEC) are among the most challenging microorganisms of public health concern. This is because they are known as foodborne pathogens and are responsible for the sporadic and epidemic incidence of hemorrhagic colitis (HC) and hemolytic uremic syndrome (HUS), worldwide [1]. STECs are found in humans and a wide range of warm blooded animals, but ruminants have been proven as the main source of food contamination and the major reservoirs for human infections [2].

The pathogenic potential of STEC strains can be attributed to various factors, such as virulence genes and Shiga toxin subtypes [3]. Also, some characteristics like serotypes and phylo-types can be regarded as indicators of pathogenic STECs. Overall, there are two primary Shiga toxins (Stx1 and Stx2), and each of them is divided into different subtypes $[4,5]$. At present, some studies have reported the relationship between some subtypes with HC and HUS infections e.g. Stx2a, Stx2c and Stx2d $[6,7]$.

Based on the role of diverse serotypes in human outbreaks, STECs can be categorized into O157 and nonO157 serogroups [8]. Recently, researchers in Europe and the United States have revealed that non-O157 serogroups such as O26, O45, O103, O111, O113, O121 and $\mathrm{O} 145$ are responsible for approximately one-thirds of STEC diseases in parallel with O157, collectively referred to as big eight $\mathrm{O}$-serogroups $[9,10]$. In contrast to developed countries, the distribution, and role of STEC serotypes are unknown in developing countries, especially in the Middle East region.

Numerous studies have been conducted on the frequency of STECs in ruminants [11, 12]; recently, comprehensive studies have been conducted on cattle which introduced them as very important reservoirs of non-O157 virulent STECs with potential pathogenicity for humans [13, 14]. Importantly, in 2015, we described the probable association of STEC from sheep and cases of uncomplicated diarrhea in children [15], but the overall public health risk associated with small ruminants STEC is unclear; some important traits like the Stx-subtypes are yet to be studied. In developing countries, meat and dairy products of small ruminants are abundantly produced and consumed in a traditional manner, which might have an impact on the epidemiology of foodborne diseases like STEC associated infections. Therefore, this project intends to investigate the pathogenic potential of Shiga toxin-producing $E$. coli strains of caprine origin through the screening of major virulence genes, Shiga toxin subtypes, big eight $\mathrm{O}$-serogroups, phylogenetic background and clonal relatedness for the first time in Iran.

\section{Methods}

Collection of STEC isolates by screening of their primary virulence genes (stx 1, stx2 and eae)

A bacterial collection consisting of 57 caprine STEC strains was chosen for this study. Theses strains were collected during several steps including: (i) sampling from feces of 250 goats and of 200 goat carcasses by sterile swabs in slaughterhouses in Iran (Kerman, Khorasan, Fars, Sistan and Baluchestan) during 2013-2016 (fecal samples were prepared using rectal swabs and for sampling from carcasses, two sterile swabs were rubbed on each internal and external areas of carcasses), (ii) transferring to laboratory within 24 hours in Cary-Blair (Oxoid, United Kingdom) transport medium [15], (iii) cultivation on MacConkey agar (Merck, Germany) at $37^{\circ}$ C for $24 \mathrm{~h}$ and isolation of suspected E. coli strains [16], (iv) confirmation of the isolates using biochemical tests including TSI (Triple Sugar Iron Agar), and IMViC (indole, methyl red, Voges-Proskauer, citrate) [16], (v) DNA extraction of $E$. coli isolates [17], (vi) molecular detection of STEC strains on the basis of main genetic markers (stx1, stx2 and eae genes) using a touchdown multiplexPCR procedure explained by Paton and Paton (2002) [18], and (vii) storage of the 57 STEC (stx-positive) isolates in Luria Bertani (LB) broth (Merck, Germany) containing $20 \%$ glycerol which finally were stored at $-80^{\circ}$ $\mathrm{C}$ for next steps.

\section{Subtyping of stx genes}

The glycerolated STEC strains were refreshed in Brain Heart Infusion (BHI) broth, (Merck, Germany) then plated on MacConkey agar and finally a single-colony was selected from each plate for DNA extraction. After DNA extraction via $\mathrm{NaOH}$ method [17], all stx-positive strains were subtyped via an accredited molecular technique described by Scheutz et al. (2012) [5] which includes a multiplex-PCR to find $s t x 1 a$, stx $1 c$ and stx $1 d$ subtypes; and also seven simplex PCR to detect st $x 2 a$, $s t x 2 b, s t x 2 c, s t x 2 d, s t x 2 e, s t x 2 f$ and $s t x 2 g$ subtypes [14]. We performed further PCRs using a $66^{\circ} \mathrm{C}$ annealing temperature for elimination of false-positive bands.

\section{Molecular screening of top eight STEC serogroups}

We evaluated attendance of eight important and human pathogenic serogroups (O26, O45, O103, O111, O113, O121, O145 and O157) among all stx-positive strains using a multiplex-PCR; this method has been developed by DebRoy et al. (2011) [19]. No other serotyping (especially by agglutination tests) was performed.

\section{Phylo-grouping of STEC strains}

For identification of phylo-groups (A, B1, B2, C, D, E, F), this project employed a procedure determined by Clermont et al (2013) [20]; first, a quadruplex PCR was used 


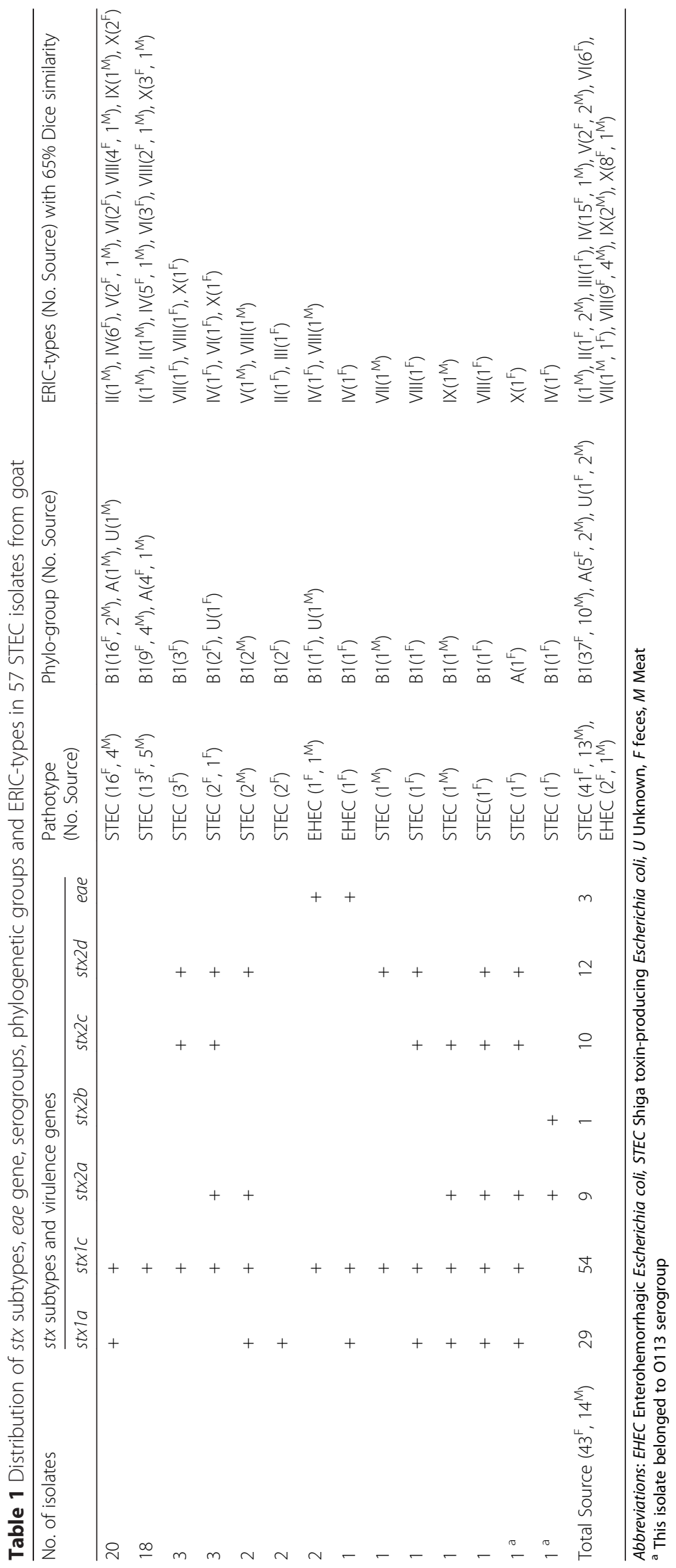


to detect four sequences called $\operatorname{arp} A$ (400 bp), chuA (288 bp), yjaA (211 bp) and TspE4.C2 (152 bp). Then, complementary PCRs were carried out on the strains which were not classified into a particular phylo-group [20,21].

\section{Clonal relatedness of STEC strains}

All 57 STEC strains were selected to fingerprinting via ERIC-PCR (enterobacterial repetitive intergenic consensus sequences - polymerase chain reaction) technique for better understanding the clonal relationship among the stx-positive strains. This method was carried out using a pair of primers called ERIC1 and ERIC2 as presented by Versalovic et al. [22]. Initially, the bacterial strains were cultured in LB broth for an overnight at $37^{\circ}$ $\mathrm{C}$, DNA was extracted by a commercial kit (Cinnagen, Iran), ERIC-PCR was done, and finally electrophoresis $(75 \mathrm{~V})$ was conducted on $2 \%$ agarose gel for $3 \mathrm{~h}$ [15].

For evaluation of ERIC-PCR results, the pictures of the bands were recorded by Gel Doc 1000 imaging system (Vilber Lourmat, France). The banding patterns of images were calibrated and analyzed using a software named 1D Pro (Totallab, United Kingdom) and the similarity of ERIC-types was indicated by the drawing of a phylogenetic tree using the unweighted pair-group with mathematic average (UPGMA) clustering method; $\geq 95 \%$ Dice similarity cut-off were considered to identify the same clonal isolates, and 65\% Dice similarity level was considered to comparative study of the STECs, in view of genotype and source.

\section{Statistical analysis}

All data about the presence or absence of variables were entered into Excel (Microsoft 2016) and SPSS (SPSS 24; IBM) programs as binomial information for descriptive statistical analysis including calculation of prevalence percentages and confidence intervals. Then the pair-wise comparison of frequencies was done in a non-parametric binomial analysis; confidence level and $P$ value were 95\% and $\leq 0.05$, respectively.

\section{Results}

Prevalence and combination patterns of stx 1 , stx 2 and eae genes in STEC strains

STEC strains were found in 14 meat and 43 fecal samples. So, the percentages reported in the present study have been mostly calculated on the basis of 57 stx-positive strains as the sample size. Overall, 43 (75.4\%) isolates possessed only stx $1,13(22.8 \%)$ strains were positive for both $s t x 1$ and stx2, and only one (1.7\%) isolate had just stx2 gene (Table 1). So, $98.2 \%$ of our STEC strains were stx 1 -positive and it is notable that stx 1 was significantly $(P<0.05)$ more prevalent than stx2 $(24.5 \%)$. The eae gene was found in $3(5.2 \%)$ isolates, introducing them as EHEC pathotype. Totally, Four diverse virulence profiles were determined which include: stx1 (40 isolates), stx1/stx2 (13 isolates), stx1/eae (3 isolates) and stx2 (1 isolate); there was no significant difference between feces and meat about the prevalence of the virulence gene profiles (Table 2).

\section{Subtypes of $s t \times 1$ and $s t x 2$ genes}

Among 56 stx 1 -positive isolates, only two subtypes were found that includes: stx $1 c$ in 54 (94.7\%) and stx $1 a$ in 29 $(50.8 \%)$ strains. Also, we recognized five various $s t x 2$ subtypes among fourteen strains that includes: $s t x 2 d$ (21.5\%), stx2c (17.5\%), stx2a (15.7\%) and stx2b (1.7\%). Besides, 11 profiles of $s t x$ subtypes were detected which st $x 1 a / s t x 1 c$ (21 strains), stx $1 c$ (20 strains), stx $1 c / s t x 2 a /$ $s t x 2 c / s t x 2 d$ (3 strains), and $s t x 1 c / s t x 2 c / s t x 2 d$ (3 strains) were the most frequent ones (Table 1).

\section{Detected O-serogroups and phylo-types}

O-serogrouping showed that all STECs did not belong to O157. Two (3.5\%) strains were found to be $\mathrm{O} 113$ and none of the other studied serogroups were identified in 55 remaining isolates (Table 1 ).

In phylo-grouping, results illustrated that majority of caprine STECs $(82.4 \%)$ are significantly $(p \leq 0.05)$ associated with the B1 phylogenetic group. Genetic markers of phylo-group A were obtained from $12.3 \%$ of strains (Table 1), while phylo-type of 3 isolates (5.3\%) were unknown. There was no significant difference between feces and meat about the prevalence of phylo-types in STEC isolates (Table 2).

\section{Clonal relatedness among STEC strains}

In this research, $E$. coli isolates with a $\geq 95 \%$ Dice similarity cut-off were considered as the same clonal isolates. Therefore, 24 unique ERIC-types were specified amongst the 57 st $x$-positive isolates.

Also, $65 \%$ similarity level was considered to compare the STECs in view of genotype and source. In this similarity cut-off, ten clusters (I to X) were defined (Fig. 1);

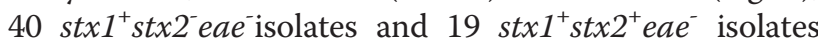

Table 2 Prevalence percentage of virulence gene profiles and phylo-groups among the STEC isolates from feces and meat

\begin{tabular}{llllllll}
\hline & \multicolumn{3}{l}{ Virulence gene profiles (No. of isolates) } & \multicolumn{4}{c}{ Phylo-group (No. of isolates) } \\
\hline Source & $s t \times 1(40)$ & $s t \times 1 / s t \times 2(13)$ & $s t \times 1 /$ eae $(3)$ & $s t \times 2(1)$ & A (7) & B1 (47) & U (3) \\
Feces (43) & $72.1 \%(31)$ & $20.9 \%(9)$ & $4.7 \%(2)$ & $2.3 \%(1)$ & $11.6 \%(5)$ & $86.1(37)$ & $2.3 \%(1)$ \\
Meat (14) & $64.3 \%(9)$ & $28.6 \%(4)$ & $7.1 \%(1)$ & $0(0)$ & $14.3 \%(2)$ & $71.4 \%(10)$ & $14.3 \%(2)$ \\
\hline
\end{tabular}




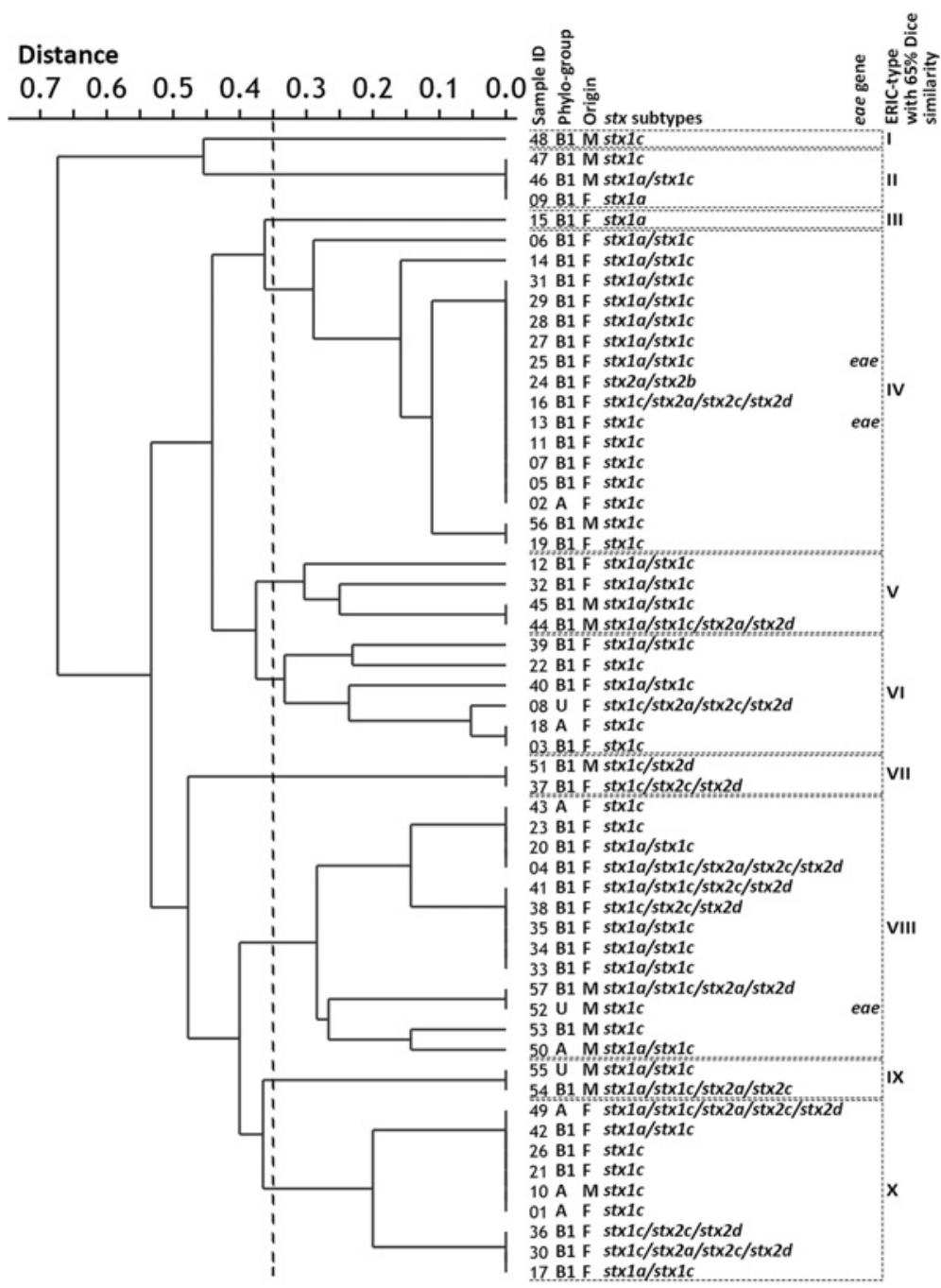

Fig. 1 Dendrogram describing the relatedness of STEC strains obtained from the goats. The cut off is in 65\% Dice similarity and the data of each isolates including phylo-group, origin of samples, primary virulence genes and stx-subtypes have mentioned after sample ID

were found in 9 and 8 ERIC-types, respectively. Two of the three $\mathrm{eae}^{+}$strains had the same ERIC-type (IV). It is notable that in 6 ERIC-types, both feces and meat sources were observed.

\section{Discussion}

In the present study, all goats had been sent to slaughterhouses for the production of raw meat. Also, most of the goats belonged to traditional farms where the goats have been exposed to cattle and sheep. These animals were in contact together at slaughterhouse in same holding pens. Accordingly, the molecular characterization of isolated STECs can clarify the role of healthy goats in the dissemination of this pathogen and pathogenic potential of caprine STECs.

In this study, frequency of $s t x 1$ was extremely high and considerably more than $s t x 2$, in agreement with the researches on goats from 2003 till today. The gene stx 1 is often identified from diarrheic or asymptomatic cases, but $s t x 2$ is mostly detected in HUS patients [23, 24]. Recently, st $x 1^{+} s t x 2^{-} e a e^{-}$strains have been reported from diarrheic children and sheep in Iran [15]. The simultaneous presence of stx 1 and stx 2 genes, which were found in about one-fifth of caprine isolates in this study, may increase the pathogenicity of such strains [25-27]. Also, the attendance of the eae gene in STEC strains resulted to the formation of a highly virulent sub-pathotype, EHEC, which was observed in three strains in the present survey; two EHEC isolates were in same ERIC-types. In this study, eae gene was found just in $s t x 1^{+} s t x 2^{-}$isolates. This finding is in agreement with some previous studies about the feces and meat of goats [11,28].

In the present survey, strains from goats were mostly negative for eae, which is similar to several previous 
researches in Europe and Asia. Hypothetically, these eae-negative strains may receive the genes encoding non-intimin adhesions via pathways of horizontal gene transfer [29]. The high percentage of our LEE-negative STEC corroborates the results of previous studies on all age groups of ruminants in Germany [30] and India [31]. It is noteworthy that some reports have shown that eaenegative STECs can also cause HC and HUS in humans, especially adult patients [32, 33].

Shiga toxin subtyping can improve understanding of the pathogenicity and epidemiology of STEC. In agreement with other studies on small ruminants and their products from 2008 to 2016 [27, 34-36], it was observed that $s t x 1 c, s t x 1 a, s t x 2 d$ and $s t x 2 c$ have approximately high prevalence. All $s t x 2^{+}$strains harbored at least one of the important subtypes including stx $2 a, s t x 2 c$ or $s t x 2 d$. These subtypes have been recognized in relation to severe STEC infections in humans [26]. This study detected the $s t x 2 a$ subtype in three-quarters of the stx2containing isolates; this is comparable with the results reported from other hosts like cattle and wild ruminants [37]. This means that stx $2 a$ is not host specific and frequently occurs in different STEC reservoirs. Some strains simultaneously carried two or three different subtypes, such as stx $1 a / s t x 1 c$, st $x 2 a / s t x 2 c / s t x 2 d$, st $x 2 a / s t x 2 c$ and $s t x 2 c / s t x 2 d$. We recently encountered this phenomenon in a similar research on cattle [14], as it has been reported from humans [38] and pigs [39].

Significantly, all our STECs belonged to non-O157 serogroups; over the past 12 years, most studies have indicated the low prevalence of O157 in goats, except a report showing $36 \%$ frequency in goat meat [11]. In the present study, two STEC strains were classified as O113 that has contributed to the development of HUS and HC in Australia [40]. Some studies have repeatedly found several less common serotypes in goats such as $\mathrm{O} 5, \mathrm{O} 126$, and $\mathrm{O} 146$ that justify the lack or low prevalence of the top eight serogroups among STECs in this study [1, 27, 35]. In our previous research on cattle, three serogroups were detected; O113 (20\%), O26 (12\%) and $\mathrm{O} 111(10 \%)$ [14]. It can be concluded that ruminants are mainly the source of non-O157 STEC strains in our region and $\mathrm{O} 113$ could be considered as one of the most prevalent serogroups which may have the potential to cause infections like previous studies [41].

Analyses of the virulence genes, O-serogroups, ERICtypes and phylogenetic background data, in relation to each other, showed that our O113 strains contain important stx 2 subtypes including $s t x 2 a, s t x 2 c$ and $s t x 2 d$; this finding is similar to the reports from HUS cases, caused by $s t x 2^{+} / \mathrm{O} 113$ strains [42] and healthy cattle [14] in some parts of the world. These strains were of two different phylogenetic and ERIC-types, showing their heterogeneity. Most members of phylo-group A just carried stx1c, excluding a clone which carried the combination of stx genes $($ stx $1 a / s t x 1 c / s t x 2 a / s t x 2 c / s t x 2 d)$; three of six strains belonging to phylo-group A were in the same ERIC-type (X) with 65\% Dice similarity and the rest of them were distributed among three different ERIC-types (Fig. 1). The members of phylo-group B1 possessed a variety of virulence profiles without any significant clonal relationship. STECs of this study were found in ten ( $\geq 65 \%$ Dice similarity) to twenty four ( $\geq 95 \%$ Dice similarity) ERIC-types indicating their high genetic diversity (Fig. 1), which is similar to a study conducted in Turkey [43].

Generally, there was no significant difference between the characteristics of meat STECs with those obtained from feces which highlights the transferability of this pathogen via meat contaminated with feces. Molecularly, st $x$-carrying bacteriophages disseminate the stx genes and made the new STEC strains [44]. One-fourth of the STEC strains were isolated from meat; most of them belonged to phylo-group B1 and were categorized into 8 ERIC-types. In this study ERIC relatedness of $s t x 1 c^{+}$ strains originated from meat and feces was observed in three ERIC-types (IV, VIII and X). This issue was observed about stx $1 a^{+}$stx $1 c^{+}$strains in one ERIC-type, too.

\section{Conclusions}

This study showed caprine STECs may have the potential to cause human infections, suggesting the study of more virulence factors. Therefore, because of the very important position of goats in the production of meat and milk in developing countries, transmission to people may occur and cause mild to severe diseases. Since the big eight serogroups were not prevalent in goats compared to cattle, this host must be searched for other serogroups. Nevertheless, based on the findings of the present study, it was suggested that the O113 should be tested for LEEnegative STEC strains recovered from suspected human infections. The presence of highly pathogenic stx subtypes in the present study revealed the public health risk of caprine STEC for the first time in Iran.

\section{Abbreviations \\ arpA: Ankyrin-like regulatory protein A gene; BHI: Brain Heart Infusion; chuA: E. coli heme-utilization gene A gene; eae: Escherichia coli attaching and effacing gene; EHEC: Enterohemorrhagic Escherichia coli strains; \\ ERIC: Enterobacterial repetitive intergenic consensus; HC: Hemorrhagic colitis; HUS: Hemolytic Uremic Syndrome; LB: Luria Bertani; LEE: Locus for enterocyte effacement; $\mathrm{NaOH}$ : Sodium Hydroxide; PCR: Polymerase Chain Reaction; SPSS: Statistical Package for the Social Sciences; STEC: Shiga toxin- producing Escherichia coli; Stx: Shiga toxin; TspE4.C2: an anonymous DNA fragment in E. coli; UPGMA: Unweighted Pair Group Method with Arithmetic Mean; yjaA: E. coli K12 gene}

\section{Acknowledgements}

We want to thank Dr. Nasrin Adib for her support in English editing of this manuscript. 


\section{Funding}

There was no financial support.

\section{Availability of data and materials}

All datasets supporting our findings are available from the corresponding author on reasonable request.

\section{Authors' contributions}

MJ and RG designed the study, MJ performed the experiments, AAIF and $M A B$ analyzed the data and $A A$ and $R G$ wrote and drafted the manuscript. $A A$ and $R G$ contributed equally in this study. All authors read and approved the final manuscript.

\section{Ethics approval and consent to participate}

There were no studies on human or laboratory animal subjects. All samples were collected from slaughtered goats with aim of meat production in Iran

\section{Consent for publication}

Not applicable.

\section{Competing interests}

The authors declare that they have no competing interests.

\section{Publisher's Note}

Springer Nature remains neutral with regard to jurisdictional claims in published maps and institutional affiliations.

\section{Author details \\ 'Applied Microbiology Research Center, Systems Biology and Poisonings Institute, Baqiyatallah University of Medical Sciences, Tehran, Iran. ${ }^{2}$ Department of Pathobiology, Faculty of Veterinary Medicine, Ferdowsi University of Mashhad, Mashhad, Iran. ${ }^{3}$ Molecular Microbiology Research Group, Shahid Bahonar University of Kerman, Kerman, Iran. ${ }^{4}$ Molecular Biology Research Center, Systems Biology and Poisonings Institute, Baqiyatallah University of Medical Sciences, Tehran, Iran.}

Received: 13 December 2017 Accepted: 2 March 2018 Published online: 16 March 2018

\section{References}

1. Mughini-Gras L, van Pelt W, van der Voort M, Heck M, Friesema I, Franz E. Attribution of human infections with Shiga toxin-producing Escherichia coli (STEC) to livestock sources and identification of source-specific risk factors, The Netherlands (2010-2014). Zoonoses Public Health. 2017; Available from: http://doi.wiley.com/https://doi.org/10.1111/zph.12403

2. Beutin L, Fach P. Detection of Shiga Toxin-Producing Escherichia coli from Nonhuman Sources and Strain Typing. Microbiol. American Society of Microbiology. 2014:2:299-319.

3. Li R, Harada T, Honjoh K, Miyamoto T. Phylogenetic analysis and Shiga toxin production profiling of Shiga toxin-producing/enterohemorrhagic Escherichia coli clinical isolates. Microb Pathog. 2010;49:246-51.

4. Balière C, Rincé A, Delannoy S, Fach P, Gourmelon M. Molecular Profiling of Shiga Toxin-Producing Escherichia coli and Enteropathogenic E. coli Strains Isolated from French Coastal Environments. Besser TE, editor. Appl Environ Microbiol. 2016:82:3913-27.

5. Scheutz F, Teel LD, Beutin L, Piérard D, Buvens G, Karch H, et al. Multicenter evaluation of a sequence-based protocol for subtyping Shiga toxins and standardizing Stx nomenclature. J Clin Microbiol. 2012;50:2951-63.

6. Melton-Celsa AR. Shiga Toxin (Stx) Classification, Structure, and Function. Microbiol Spectr. 2014;2

7. Skinner C, Patfield S, Stanker LH, Fratamico P, He X. New high-affinity monoclonal antibodies against Shiga toxin 1 facilitate the detection of hybrid Stx1/Stx2 in vivo. PLoS One. 2014;9:e99854.

8. Smith JL, Fratamico PM, Gunther NWT. Shiga toxin-producing Escherichia coli. Adv Appl Microbiol. 2014;86:97

9. Pihkala N, Bauer N, Eblen D, Evans P, Johnson R, Webb J, et al. Risk profile for pathogenic non-0157 Shiga toxin-producing Escherichia coli (non-0157 STEC). US Dep. Agric. Food Saf. 2012:1-64.

10. Authority EFS. The European Union summary report on trends and sources of zoonoses, zoonotic agents and food-borne outbreaks in 2013. EFSA J. $2015 ; 13$
11. Momtaz H, Safarpoor Dehkordi F, Rahimi E, Ezadi H, Arab R. Incidence of Shiga toxin-producing Escherichia coli serogroups in ruminant's meat. Meat Sci. 2013;95:381-8.

12. Khandaghi J, Shayeghi J, Khakpoor M, Barzgari A. Shiga toxin-producing Escherichia coli O26 strains in bovine feces in East-Azarbaijan. Iran. Sci Res Essays. 2011;6:39-43.

13. Dong H-J, Lee S, Kim W, An J-U, Kim J, Kim D, et al. Prevalence, virulence potential, and pulsed-field gel electrophoresis profiling of Shiga toxinproducing Escherichia coli strains from cattle. Gut Pathog. 2017;9:22.

14. Jajarmi M, Imani Fooladi AA, Badouei MA, Ahmadi A. Virulence genes, Shiga toxin subtypes, major O-serogroups, and phylogenetic background of Shiga toxin-producing Escherichia coli strains isolated from cattle in Iran. Microb Pathog. 2017:109:274-9.

15. Askari Badouei M, Jajarmi M, Mirsalehian A. Virulence profiling and genetic relatedness of Shiga toxin-producing Escherichia coli isolated from humans and ruminants. Comp. Immunol. Microbiol. Infect Dis. 2015;38:15-20.

16. Markey B, Leonard F, Archambault M, Cullinane A, Maguire D. Clinical Veterinary Microbiology. Elsevier Health Sciences. 2013;

17. Jajarmi M, Ghanbarpour R, Sharifi H, Golchin M. Distribution Pattern of EcoR Phylogenetic Groups Among Shiga Toxin-Producing and Enteropathogenic Escherichia coli Isolated From Healthy Goats. Int J Enteric Pathog. 2015:3

18. Paton AW, Paton JC. Direct Detection and Characterization of Shiga Toxigenic Escherichia coli by Multiplex PCR for stx1, stx2, eae, ehxA, and saa. J Clin Microbiol. 2002;40:271-4.

19. DebRoy C, Roberts E, Valadez AM, Dudley EG, Cutter CN. Detection of Shiga Toxin-Producing Escherichia coli O26, O45, 0103, 0111, 0113, 0121, 0145, and 0157 Serogroups by Multiplex Polymerase Chain Reaction of the wzx Gene of the O-Antigen Gene Cluster. Foodborne Pathog Dis. 2011:8:651-2.

20. Clermont O, Christenson JK, Denamur E, Gordon DM. The Clermont Escherichia coli phylo-typing method revisited: improvement of specificity and detection of new phylo-groups. Environ Microbiol Rep. 2013;5:58-65.

21. Clermont O, Gordon DM, Brisse S, Walk ST, Denamur E. Characterization of the cryptic Escherichia lineages: rapid identification and prevalence. Environ Microbiol. 2011;13:2468-77.

22. Versalovic J, Koeuth T, Lupski R. Distribution of repetitive DNA sequences in eubacteria and application to finerpriting of bacterial enomes. Nucleic Acids Res. 1991;19:6823-31.

23. Orden JA, Ruiz-santa-quiteria JA, Blanco M, Blanco JE, Mora A, Cid D, et al. Prevalence and characterization of Vero cytotoxin-producing Escherichia coli isolated from diarrhoeic and healthy sheep and goats. Epidemiol Infect. 2003;130:313-21.

24. Burnens AP, Boss P, Ørskov F, Ørskov I, Schaad UB, Müller F, et al. Occurrence and phenotypic properties of verotoxin producingEscherichia coli in sporadic cases of gastroenteritis. Eur J Clin Microbiol Infect Dis. 1992;11:631-4.

25. Friedrich AW, Bielaszewska M, Zhang W-L, Pulz M, Kuczius T, Ammon A, et al. Escherichia coli Harboring Shiga Toxin 2 Gene Variants: Frequency and Association with Clinical Symptoms. J Infect Dis. 2002:185:74-84.

26. Vu-Khac H, Cornick NA. Prevalence and genetic profiles of Shiga toxinproducing Escherichia coli strains isolated from buffaloes, cattle, and goats in central Vietnam. Vet Microbiol. 2008;126:356-63.

27. Rahimi E, Kazemeini HR, Salajegheh M. Escherichia coli O157: H7/NM prevalence in raw beef, camel, sheep, goat, and water buffalo meat in Fars and Khuzestan provinces. Iran. Vet Res Forum. 2012:3:15.

28. Cortés C, De la Fuente R, Blanco J, Blanco M, Blanco JE, Dhabi G, et al. Serotypes, virulence genes and intimin types of verotoxin-producing Escherichia coli and enteropathogenic E. coli isolated from healthy dairy goats in Spain. Vet Microbiol. 2005;110:67-76.

29. Newton HJ. Shiga Toxin-producing Escherichia coli Strains Negative for Locus of Enterocyte Effacement. Emerg Infect Dis. 2009;15:372-80.

30. Zschock M, Hamann HP, Kloppert B, Wolter W. Shiga-toxin-producing Escherichia coli in faeces of healthy dairy cows, sheep and goats: prevalence and virulence properties. Lett Appl Microbiol. 2000;31:203-8.

31. Bhat MA, Nishikawa Y, Wani SA. Prevalence and virulence gene profiles of Shiga toxin-producing Escherichia coli and enteropathogenic Escherichia coli from diarrhoeic and healthy lambs in India. Small Rumin Res. 2008:75:65-70.

32. Beutin L, Krause G, Zimmermann S, Kaulfuss S, Gleier K. Characterization of Shiga Toxin-Producing Escherichia coli Strains Isolated from Human Patients in Germany over a 3-Year Period. J Clin Microbiol. 2004;42:1099-108.

33. Beutin L, Geier D, Zimmermann S, Aleksic S, Gillespie HA, Whittam TS. Epidemiological relatedness and clonal types of natural populations of 
Escherichia coli strains producing Shiga toxins in separate populations of cattle and sheep. Appl Environ Microbiol. 1997;63:2175-80.

34. Martin A, Beutin L. Characteristics of Shiga toxin-producing Escherichia coli from meat and milk products of different origins and association with food producing animals as main contamination sources. Int J Food Microbiol. 2011;146:99-104.

35. Bai L, Hurley D, Li J, Meng Q, Wang J, Fanning S, et al. Characterisation of multidrug-resistant Shiga toxin-producing Escherichia coli cultured from pigs in China: co-occurrence of extended-spectrum $\beta$-lactamase- and mcr1-encoding genes on plasmids. Int J Antimicrob Agents. 2016;48:445-8.

36. Horcajo P, Domínguez-Bernal G, De La Fuente R, Ruiz-Santa-Quiterai JA, Orden JA. Association of vt1c with verotoxin-producing Escherichia coli from goats and sheep. J Vet diagnostic Investig. 2010;22:332-4.

37. Hofer E, Cernela N, Stephan R. Shiga Toxin Subtypes Associated with Shiga Toxin-Producing Escherichia coli Strains Isolated from Red Deer, Roe Deer, Chamois, and Ibex. Foodborne Pathog Dis. 2012;9:792-5.

38. Byrne L, Vanstone GL, Perry NT, Launders N, Adak GK, Godbole G, et al. Epidemiology and microbiology of Shiga toxin-producing Escherichia coli other than serogroup 0157 in England, 2009-2013. J Med Microbiol. 2014; 63:1181-8.

39. Baranzoni GM, Fratamico PM, Gangiredla J, Patel I, Bagi LK, Delannoy S, et al. Characterization of Shiga Toxin Subtypes and Virulence Genes in Porcine Shiga Toxin-Producing Escherichia coli. Front Microbiol. 2016;7

40. Paton AW, Woodrow MC, Doyle RM, Lanser JA, Paton JC. Molecular Characterization of a Shiga ToxigenicEscherichia coli O113: H21 Strain Lacking eaeResponsible for a Cluster of Cases of Hemolytic-Uremic Syndrome. J Clin Microbiol. 1999;37:3357-61.

41. Feng P, Delannoy S, Lacher DW, Bosilevac JM, Fach P. Characterization and Virulence Potential of Serogroup 0113 Shiga Toxin-Producing Escherichia coli Strains Isolated from Beef and Cattle in the United States. Journal of food protection. 2017;80(3):383-91.

42. Bonardi S, Alpigiani I, Tozzoli R, Vismarra A, Zecca V, Greppi C, et al. Shiga toxin-producing Escherichia coli O157, O26 and O111 in cattle faeces and hides in Italy. Vet Rec Open. 2015;2:e000061.

43. Türkyllmaz S, Eskiizmirliler S, Tunaligil S, Bozdogan B. Identification, characterization and molecular epidemiology of Escherichia coli isolated from lamb and goat kids with diarrhoea. Acta Vet Brno. 2014:82:357-62

44. Solheim HT, Sekse C, Urdahl AM, Wasteson Y, Nesse LL. Biofilm as an environment for dissemination of stx genes by transduction. Appl Environ Microbiol. 2013;79(3):896-900

\section{Submit your next manuscript to BioMed Central and we will help you at every step:}

- We accept pre-submission inquiries

- Our selector tool helps you to find the most relevant journal

- We provide round the clock customer support

- Convenient online submission

- Thorough peer review

- Inclusion in PubMed and all major indexing services

- Maximum visibility for your research

Submit your manuscript at www.biomedcentral.com/submit

) Biomed Central 